\title{
Food, "culture," and sociality in Drosophila
}

\section{Mathieu Lihoreau* and Stephen J. Simpson}

School of Biological Sciences, The Charles Perkins Centre, The University of Sydney, Sydney, NSW, Australia

*Correspondence: mathieu.lihoreau@sydney.edu.au

\section{A commentary on}

Spread of social information and dynamics of social transmission within Drosophila groups

by Battesti, M., Moreno, C., Joly, D., and Mery, F. (2012). Curr. Biol. 22, 309-313.

Communication with and learning from others are key features of social life. We humans rely extensively on the advice of others before making important decisions. Social insects too, such as bees and ants, use social information to learn about foraging opportunities and engage in collective tasks (Dussutour and Simpson, 2009; Seeley et al., 2012). Growing interest into the learning abilities of small-brained animals has revealed that social learning in insects is more diverse and more common than previously thought (Leadbeater and Chittka, 2007), thus offering new opportunities for comparative analyses of the role of cognition in the regulation of social behavior across a rich spectrum of social forms.

Recently, the fruit fly Drosophila melanogaster (Figure 1A) has emerged as a key species for studying social learning in simple insect groups (Mery et al., 2009; Sarin and Dukas, 2009). Flies aggregate on food resources, where they feed, reproduce, lay eggs, and glean information from each other. Writing in a recent issue of Current Biology, Battesti et al. (2012) present evidence that Drosophila females not only use social information to select oviposition substrates, but also that these socially acquired preferences can propagate and stabilize within groups, a phenomenon resembling cultural transmission of knowledge in vertebrates (Laland, 2008).

The authors used a three-step experimental paradigm (Figure 1B). A group of flies was first trained to associate an aversive gustatory cue (quinine) with an artificial flavor (banana or strawberry) characterizing one of two standard oviposition media (agar and sugar). These conditioned "demonstrators" were then caged with naïve "observers" with two fresh, flavored media (without quinine). In the critical test phase, demonstrators and observers were exposed separately to the two flavored media. Social transmission occurred if the oviposition choices of observers mirrored that of demonstrators.

Using this methodology, Battesti et al. (2012) first showed that observer flies relied heavily on social information and acquired oviposition preferences from demonstrators, even if they had the opportunity to sample the two equally suitable media during the transmission phase, thus confirming previous observations in this species (Sarin and Dukas, 2009).

The authors next investigated the mechanisms of social transmission and showed that social learning did not occur when observers were exposed to social cues only (freshly laid eggs and aggregation pheromone) on one of the two media. Social transmission, however, always occurred when observers interacted directly with demonstrators, even if the media were unflavored. Although the precise mechanism of social learning remains an open question, presumably, it can be explained by relatively simple associative learning processes occurring during physical contacts between observer and demonstrator flies through the perception of the olfactory cues (banana or strawberry flavors) carried by the demonstrators. Such mechanism, for instance, underpins social transmission of food preferences in rats (Galef et al., 1985).

In a third set of experiments, Battesti et al. (2012) have gone a step further into the understanding of how flies balance their use of social and personal information. By exposing observers to the two flaexperimental paradigm they demonstrated that the socially acquired preference vanished if observers were allowed to acquire personal information after the transmission phase. Considering the short lifespan of Drosophila (Lee et al., 2008), rapidly adopting the behavior of the majority may provide naïve flies with cues to choices that are locally adaptive and prevent costly trial and error. However, if information about resources is abundant and not costly to vored media at the different phases of the

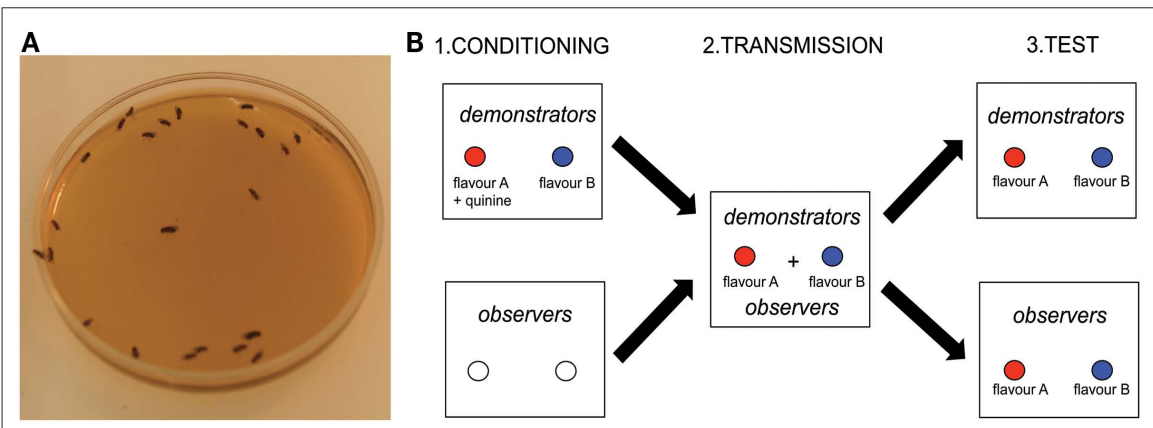

FIGURE 1 | Social learning of oviposition preferences in Drosophila melanogaster. (A) Drosophila females aggregated on a standard oviposition medium (credit ML). (B) Battesti et al. (2012) tested the role of social information use in the oviposition decisions of Drosophila females exposed to two equally rewarding oviposition media characterized by a distinct artificial flavor (A or B). The same general paradigm was used in all experiments. During the conditioning phase, "demonstrator" flies were conditioned to associate flavor A with quinine (non-preferred medium) and flavor B with the absence of quinine (preferred medium). "Observers" were trained with odorfree media and thus remained naiive to the flavors. During the transmission phase, demonstrators and observers were exposed together to the two flavored media without quinine. During the test phase, demonstrators and observers were exposed separately to the two flavored media. Social transmission was successful if the oviposition preference of observers mirrored that of demonstrators. 
sample, experienced individuals may rely more on their personal knowledge (Boyd and Richerson, 1985).

So far, the authors had shown that Drosophila females use social information to choose oviposition media providing that they do not have an extensive knowledge of their environment, but not whether these socially acquired behaviors can percolate and stabilize durably within groups. Battesti et al. (2012) addressed this question by testing if the information transmitted from demonstrators to first-order observers could again be passed from first-order observers to second-order observers. After two transmission phases, they found that second-order observers exhibited the same oviposition preferences as demonstrators. First-order observers, however, no longer demonstrated a preference due to their extensive accumulation of personal information. This last result elegantly illustrates how behavioral adaptations potentially spread and maintain in natural populations of flies, providing a frequent turnover between naïve and experimented individuals.

What are the implications of this study? The fact that Drosophila make a sophisticated use of social information is certainly an important discovery to understand the full spread of social learning strategies in invertebrates, but may not surprise those who have repeatedly showed how smallbrained insects solve a range of complex cognitive problems, including rule learning (Giurfa et al., 2001) or route optimization (Lihoreau et al., 2012). This study together with other recent findings on the behavioral ecology of fruit flies (Sokolowski, 2010) reveal a surprising diversity of social behavior in a model organism that is not traditionally considered as "social" (Costa, 2006). A better recognition of this behavioral repertoire in Drosophila thus provides a rare opportunity to exploit the wealth of resources that a model species has to offer to examine the cognitive dimension of insect sociality.

Of course, Drosophila might tell us little about the cognitive processes behind symbolic communication, altruism, or the division of labor in insect societies (Chittka and Niven, 2009). Nonetheless, accumulated knowledge on the genetic and neurobiology of Drosophila makes it possible to examine the neural circuitries underlying emergent social behavior with unparalleled ease. At the individual level, such work might allow us to better characterize how social interactions fashions brains and whether there is a "social brain" (Dunbar and Shultz, 2007). At the group level, understanding the neural determinants of aggregation processes in Drosophila (Tinette et al., 2004), offers considerable promise to explore collective decision dynamics and swarm intelligence phenomena (Krause et al., 2010) in animal groups exploiting complex nutritional environments where resources vary both in quantity and quality. Ultimately, a greater utilization of Drosophila as a "social" model organism might allow us to clarify the interplay between the evolution of cognition and social behavior.

\section{ACKNOWLEDGMENTS}

This work was supported by the Australian Research Council through a Laureate Fellowship to Stephen J. Simpson and a postdoctoral fellowship to Mathieu Lihoreau.

\section{REFERENCES}

Battesti, M., Moreno, C., Joly, D., and Mery, F. (2012). Spread of social information and dynamics of social transmission within Drosophila groups. Curr. Biol. 22, 309-313.

Boyd, R., and Richerson, P. J. (1985). Culture and the Evolutionary Process. Chicago, IL: University of Chicago Press.

Chittka, L., and Niven, J. (2009). Are bigger brains better? Curr. Biol. 19, R995-R1008.

Costa, J. T. (2006). The Other Insect Societies. Cambridge, MA: Harvard University Press.

Dunbar, R. I. M., and Shultz, S. (2007). Evolution in the social brain. Science 317, 1344-1347.
Dussutour, A., and Simpson, S. J. (2009). Communal nutrition in ants. Curr. Biol. 19, 740-744.

Galef, B. G., Kennett, D. J., and Stein, M. (1985). Demonstrator influence on observer diet preference - effects of simple exposure and the presence of a demonstrator. Anim. Learn. Behav. 13, 25-30.

Giurfa, M., Zhang, S., Jenett, A., Menzel, R., and Srinivasan, M. (2001). The concepts of "sameness" and "difference" in an insect. Nature 410, 930-933.

Krause, J., Ruxton, G. D., and Krause, S. (2010). Swarm intelligence in animals and humans. Trends Ecol. Evol. (Amst.) 25, 28-34.

Laland, K. N. (2008). Animal cultures. Curr. Biol. 18, R366-R370.

Leadbeater, E., and Chittka, L. (2007). Social Learning in insects-from miniature brains to consensus building. Curr. Biol. 17, R703-R713.

Lee, K. P., Simpson, S. J., Clissold, F. J., Brooks, R., Ballard, J. W. O., Taylor, P. W., Soran, N., and Raubenheimer, D. (2008). Lifespan and reproduction in Drosophila: new insights from nutritional geometry. Proc. Natl. Acad. Sci. U.S.A. 105, 2498-2503.

Lihoreau, M., Chittka, L., Le Comber, S. C., and Raine, N.E. (2012). Bees do not use nearest-neighbour rules for optimization of multi-location routes. Biol. Lett. $8,13-16$.

Mery, F., Valera, S. A. M., Danchin, E., Blanchet, S., Parejo, D., Coolen, I., and Wagner, R. H. (2009). Public versus personal information for mate copying in an invertebrate. Curr. Biol. 19, 730-734.

Sarin, S., and Dukas, R. (2009). Social learning about egg-laying substrates in fruitflies. Proc. Biol. Sci. 276, 4323-4328.

Seeley, T. D., Visscher, P. K., Schlegel, T., Hogan, P. M., Franks, N. R., and Marshall, J.A. R. (2012). Stop signals provide cross inhibition in collective decision-making by honeybee swarms. Science 335, 109-111.

Sokolowski, M. B. (2010). Social interactions in "simple" model systems. Neuron 65, 780-794.

Tinette, S., Zhang, L., and Robichon, A. (2004). Cooperation between Drosophila flies in searching behavior. Genes Brain Behav. 3, 39-50.

Received: 12 April 2012; accepted: 09 May 2012; published online: 28 May 2012.

Citation: Lihoreau M and Simpson SJ (2012) Food, "culture," and sociality in Drosophila. Front. Psychology 3:165. doi: 10.3389/fpsyg.2012.00165

This article was submitted to Frontiers in Comparative Psychology, a specialty of Frontiers in Psychology.

Copyright $\odot 2012$ Lihoreau and Simpson. This is an openaccess article distributed under the terms of the Creative Commons Attribution Non Commercial License, which permits non-commercial use, distribution, and reproduction in other forums, provided the original authors and source are credited. 